\title{
DUAS NOVAS ESPÉCIES DE TUNAIMA FENNAH, 1968 (HOMOPTERA, CERCOPIDAE) ${ }^{1}$
}

\author{
Gervásio Silva Carvalho²
}

\begin{abstract}
Two new brazilian species of Tunaima Fennah, 1968 are described: T. brunneoaurantiaca sp.n. (from São Paulo and Paraná) and T. brunneolutea sp.n. (from Paraná and Rio Grande do Sul).

\section{INTRODUÇÃO}

Tunaima foi descrito por FENNAH, em 1968:183, incluindo as espécies Monecphora brunneorubra Lallemand, 1927:116, designada como tipo; $M$. decorata Lall., 1924:382; $M$ fossor Lall., 1938:140; M. insignifica Metcalf, 1961:227; e, $M$. trifasciata Lall., 1938:141. Posteriormente, FENNAH, 1979:269, transferiu as espécies Tomaspis walkeri Lallemand, 1912:98; Monecphora pellucens Stal, 1862:14; e M. ferranti Lallemand, 1924:381 para o gênero em questão, perfazendo um total de oito espécies, todas da regiăo neotropical.

runaima está definido nos trabalhos de FENNAH, 1968:183 e 1979:269, porém, do estudo efetuado, enfatizando-se a análise feita na genitália, estabeleceu-se como cazacterísticas genéricas o posclípeo um pouco comprimido lateralmente, de perfil superficialmente convexo não interrompido na junção com o anteclípeo; rostro atingindo o mesotrocânter; asas com veia Cul gradualmente alargada na base; pigóforo com um dente lateral, placa subgenital longa e estreita, apresentando um par de processos espithosos mediano dorsal; ovipositor com um par de processos basais na primeira valva.

Veste trabalho acrescentam-se mais duas espécies ao gênero: $T$. brunneoaurantiaca sp.n. e $T$. brunneolutea sp.n. provenientes dos estados de São Paulo, Paraná e Rio Grande do Sul.
\end{abstract}

\section{Tunaima srunneocarantiaca sp.n.}

$$
\text { (Figs. 1-5, } 11 \text { e 12) }
$$

Caracteres diagnósticos: coloração geral marron-alaranjada escura; cabeça alaranada; pronoto com faixa no terço anterior alaranjado e o restante marron escuro; tégmias opacas, pilosidade decumbente alaranjada, terço basal algo mais claro, com duas aanchas costais alaranjadas, uma no fim do terço basal e outra no fim do terço mediato e início do apical. Posclípeo, tórax, abdômen e pernas vermelhas. 
Revta bras. Zool.
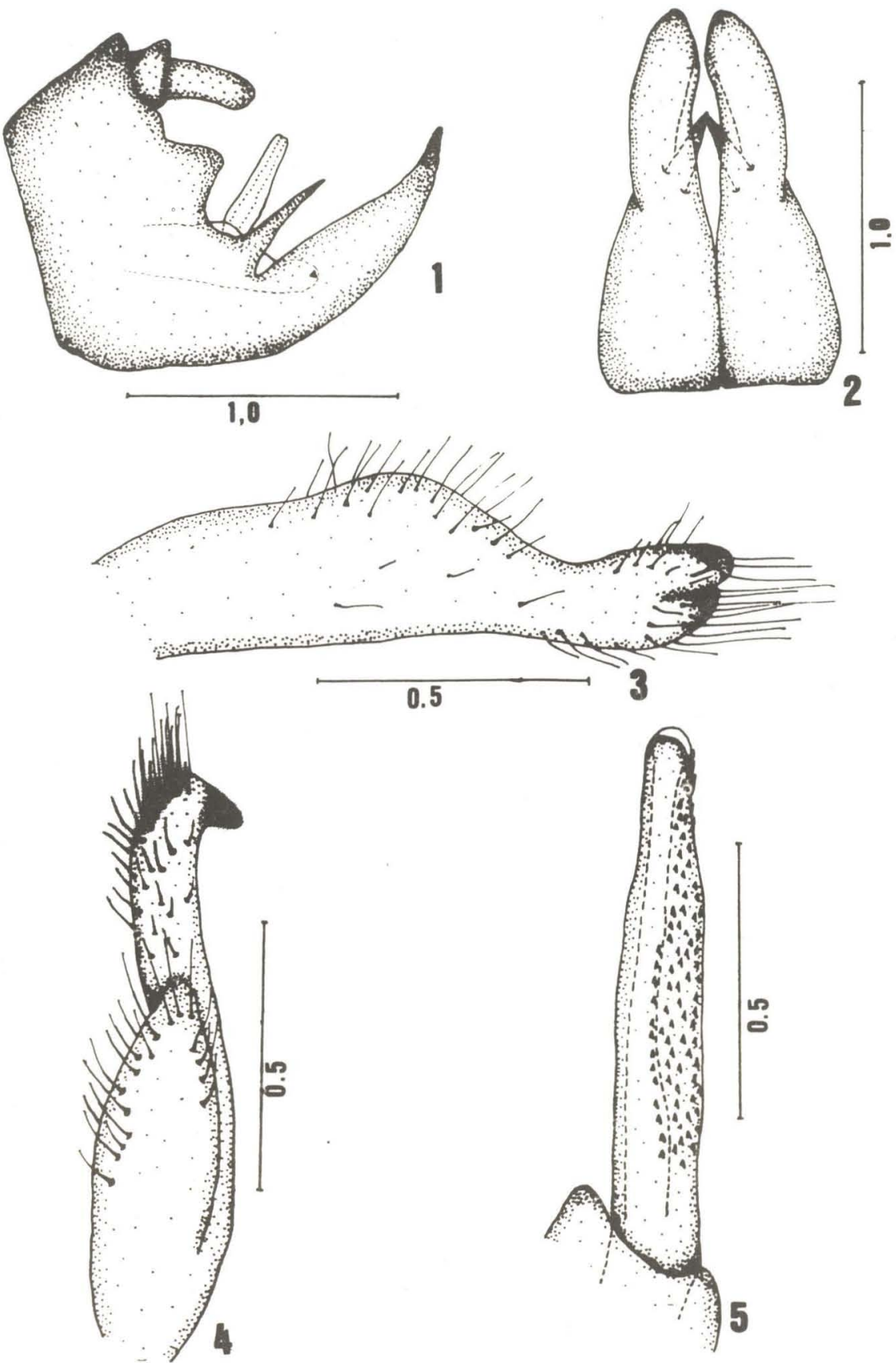

Fig. 1-5 - Tunaima brunneoaurantiaca sp. n.: 1. - vista lateral do pigóforo; 2. - vista inferior das placas subgenitais; 3. - vista lateral do parâmero esquerdo; 4. - vista dorsal do parâmero esquerdo; 5 . - vista lateral esquerda do edeago. Escala em milímetros. 

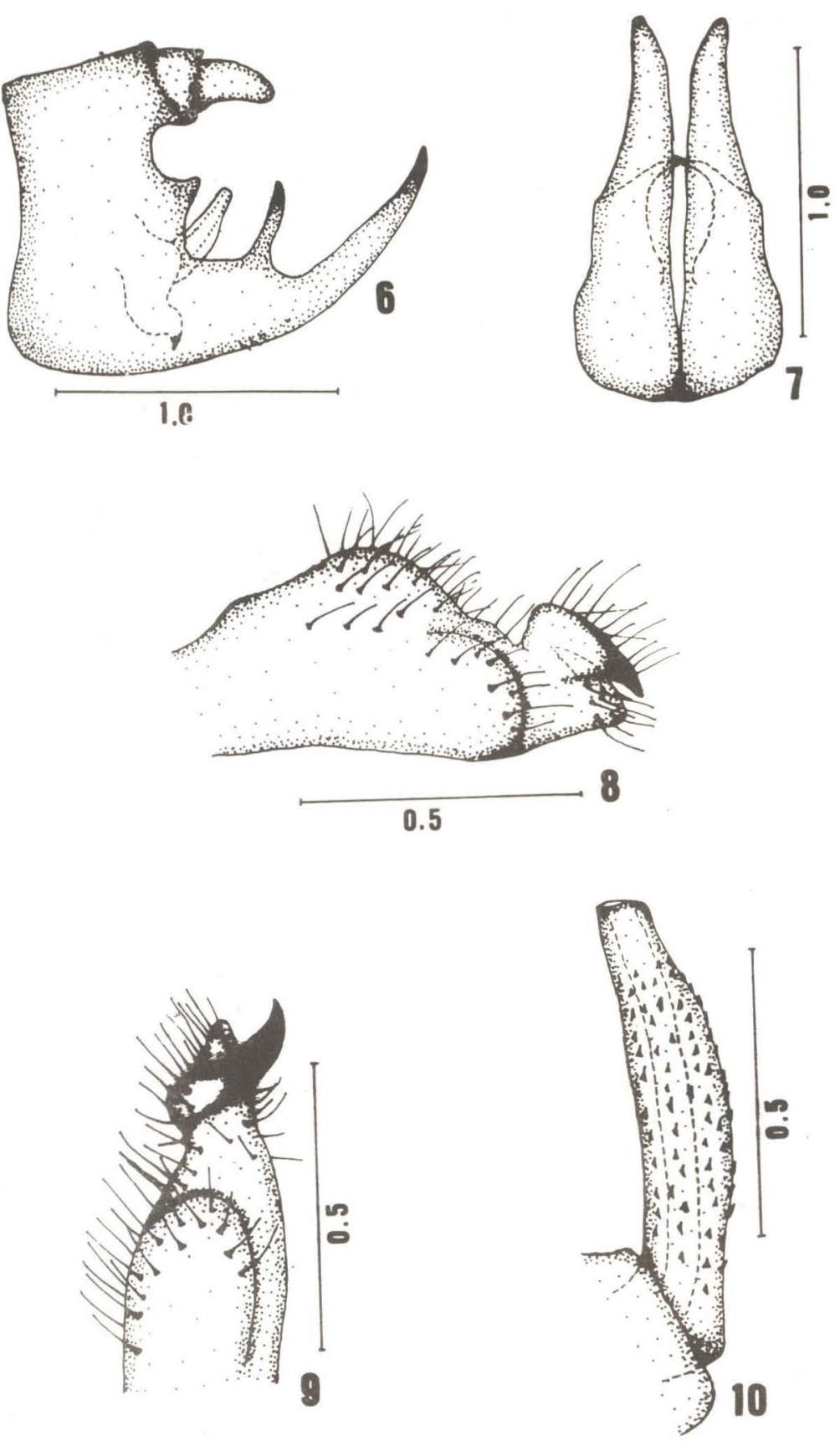

Figs. ن-10 - Tunaima brunneolutea sp.n.: 6. - vista lateral do pigóforo; 7, - vista inferior das placas subgenitais; 8. - vista lateral do parâmero esquerdo;9. - vista dorsal do parâmero esquerdo; 10. - vista lateral esquerda do edeago. Escala em milímetros. 
Revta bras. Zool
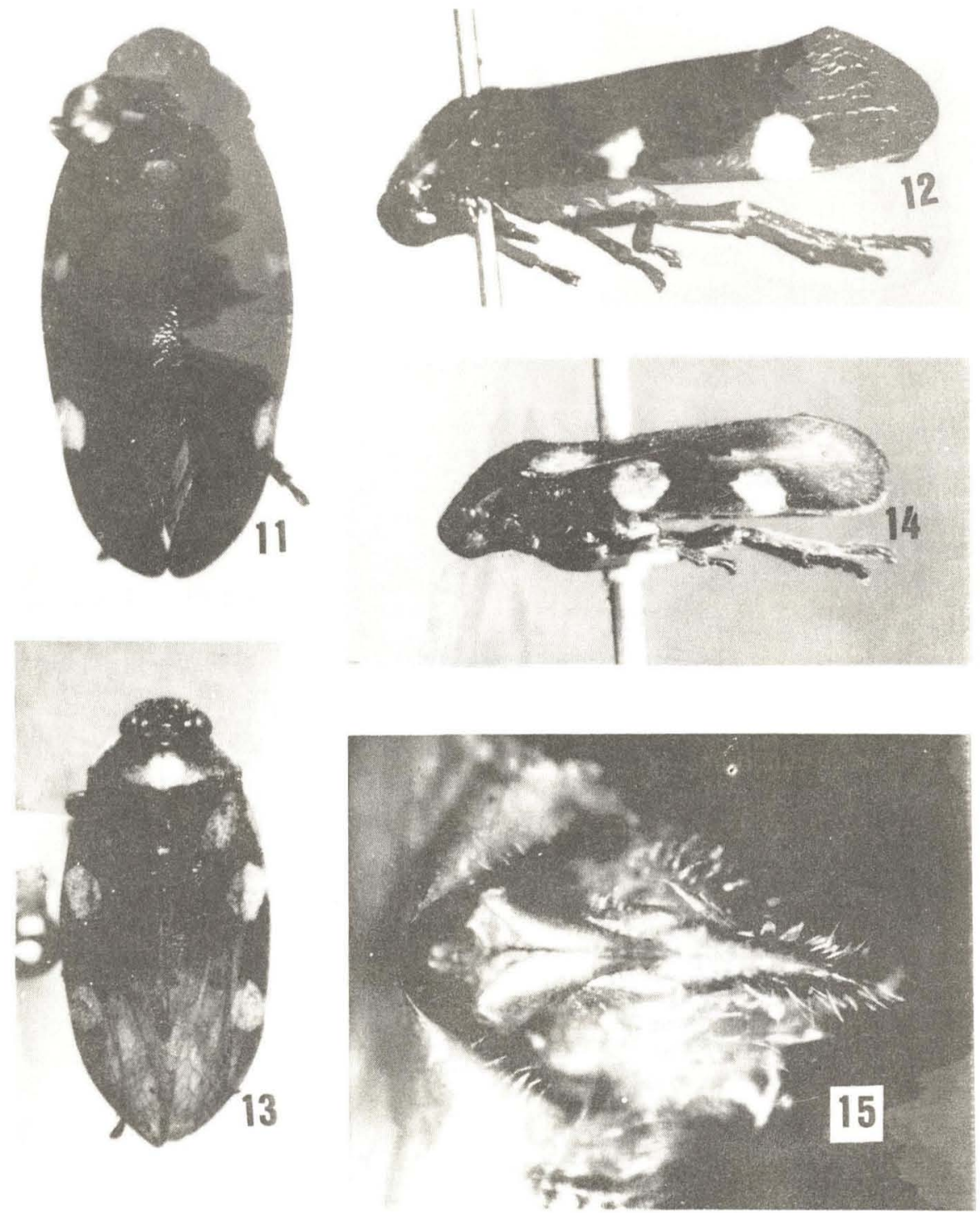

Figs. 11-15 - Tunaima brunneoaurantiaca sp.n. e Figs. 13-15. Tunaima brunneolutea sp.n.: 11 e 13 vista dorsal; 12 e 14. - vista lateral esquerda; 15. - vista inferior do ovipositor. 
Medidas (em mm). Holótipo/Média de 5 machos/Amplitude comprimento total: $11,81 / 11,56 / 11,81-11,31$; comprimento das tégminas: 9,90/9,62/9,90-9,30; largura máxima das tégminas: $3,56 / 3,38 / 3,56-3,06$; largura máxima do pronoto: $4,00 / 3,87$ | 4,00-3,76; largura máxima da cabeç̧̧a: 2,27/2,27/2,32-2,24; distância interocular: 1,38/1,33/1,38-1,30; largura do tilo: 0,65/0,66/0,68-0,65.

Típo e localidade tipo: Holótipo macho de "Est. Biol. Boracéia/Salesópolis, SPBr/15-16.X.1983/Ex. DZUSP". Parátipos: 4 machos de "S. José do Barreiro/Serra da Bocaina/Faz. do Bonito, SP/M.A. Vulcano col."; 1 macho de "Est. Biol. Boracéia/ Salesópolis, SP-BR/8-9.X.1983/Ex. DZUSP"; 1 macho de "S. Paulo/Boracéia/F. Lane/ 7.X.55"; 1 macho de "S. Paulo/Itapecirica/F. Lane/18.X.44"; e, 1 macho de "MorretesPR/19-20.X.1984/CIIF (luminosa)". O holótipo e o exemplar de Morretes-PR, estão depositados no Museu do Departamento de Zoologia da Universidade Federal do Paraná, os demais, com excessão do coletado em Itapecirica, inclú́do na coleção do autor, estão no Museu de Zoologia da Universidade de São Paulo.

Descrição: Holótipo macho. Cabeça 3,1 vezes mais larga que o comprimento do vértice, de cor alaranjada; com posclípeo vermelho e carena mediana enegrecida: anteclípeo vermelho; rostro avermelhado com o último artículo negro. Olhos ovalados, transversais, negros. Vértice mais ou menos liso, brilhante e com pilosidade conspícua, elevado no meio, sem carena, com duas impressões laterais aos ocelos, iniciando-se no ângulo posterior do tilo, dirigindo-se para trás até as fóveas, estas bem pronunciadas. Tilo quadrangular, mais largo do que longo, com margem anterior algo angulado e posterior sinuosa. Lobos supra antenais algo enegrecidos. Ocelos de diâmetro igual a 0,48 do espaço entre eles; mais próximos entre si que dos olhos e da margem posterior da cabeça. Antenas negras; escapo, em vista dorsal escondido pelos lobos supra antenais; pedicelo cilindrico de comprimento 1,5 vezes maior que seu diâmetro, parcialmente visível por cima; com um conjunto dorso-lateral externo de cerdas; flagelo com corpo basal subcilíndrico, de largura menor que a do pedicelo; estilo longo e fino; arista com comprimento quase igual ao diâmetro do corpo basal, implantada inferiormente e no mesmo plano do estilo. Posclípeo intumecido um pouco comprimido lateralmente, superficialmente convexo de perfil, não interrompendo na junção com o anteclípeo, com carena mediana reduzindo-se em direção ao anteclípeo, sulcos transversais evidentes, com fila de cerdas. Anteclípeo razoavelmente comprimido. Rostro atingindo a margem posterior das coxas mesotorắcicas.

Pronoto com faixa no terço anterior, continuando-se pela margem ântero-lateral, laranja e o restante marron-escuro; finamente puncturado; pilosidade decumbente; forma hexagonal; levemente arqueado, convexo, sem carena média; duas diminutas impressões junto a linha média e em posição posterior à faixa laranja e duas grandes laterais a esta; margem anterior reta, ântero-laterais levemente convexas e arqueadas, pósterolaterais levemente sinuosas e posterior chanfrada. Escutelo triangular, côncavo medianamente e com estrias transversais, de coloração laranja-enegrecida. Tégminas marron-alaranjado escuro, com idêntica pontuação e pilosidade do pronoto; terço basal levemente mais claro, duas manchas no cório, na margem costal; uma no fim do terço basal, e a outra no fim do terço mediano início do apical, ambas quase atingindo a veia $\mathrm{M}$, alaranjadas; comprimento igual a 2,78 vezes sua largura; venação razoavelmente distinta; $\mathrm{Me} \mathrm{Cu}$ unidas num curto trajeto, próximo à base. Asas vítreas, venação bem distinta, com 4 células apicais; lobos hamulifferos triangulares, com 3 hâmulos; veia Cul gradualmente alargada na base. Pernas de coloração vermelha, com extremidades enegrecendo-se, principalmente os tarsos; tíbias posteriores com 2 espinhos laterais, o basal menor, ligeiramen: 
te maior que os apicais, estes em número de 10, distribuídos em 2 filas; basitarsos posteriores com 18 espinhos apicais, dispostos em uma fileira em forma de "V"; postarso com processo subungueal reduzido. Tórax e abdomen ventralmente avermelhados.

Genitália: Pigóforo marron-alaranjado claro, com um dente látero-posterior; placa subgenital bipartida, com extremidade ponteaguda e igual processo na base, dorsalmente; parâmeros com elevação basal e dente distal voltado para fora; edeago cilíndrico reto, simples, com dentículos distribuídos látero-posteriomente.

Discussão: próxima a $T$. insignifica (Lall.), da Colômbia, por apresentar cabeça e faixa anterior no pronoto alaranjado, diferindo, porém, pelo restante deste último que possui mais duas outras faixas, uma negra e outra amarela; tégminas também com duas manchas, porém amarelas e a anterior atingindo metade do clavo. Diferencia-se, ainda, pelo tamanho, sendo esta mais de 1,5 milímetros menor.

\section{Tunaima brunneolutea sp.n.}

(Figs. 6-10, 13-15)

Caracteres diagnósticos. Coloração geral marron-amarelado; cabeça vermeiha, tendendo ao marron-avermelhado escuro próximo aos olhos; pronoto com faixa no terço anterior vermelha, o restante amarelado, com uma faixa látero-posterior de largura variável, negra; escutelo, posclípeo, tórax, abdomen e pernas vermelhas; tégminas algo transparentes marron-amarelado, com três manchas amarelas: duas no cório, próximas a margem costal, no fim do terço anterior e do mediano, e a terceira no clavo basalmente.

Medidas (em mm). Holótipo/Média de 4 machos/Amplitude/Fêmea:

Comprimento total: $9,55 / 9,64 / 9,93-9,55 / 10,18$; comprimento das tégminas: $8,11 / 8,11 / 8,31-7,92 / 8,51$; largura máxima das tégminas: $2,92 / 2,80 / 2,92-2,67 / 2,82$; largura máxima do pronoto: $3,31 / 3,44 / 3,51-3,31 / 3,46$; largura máxima da cabeça: 2,00/2,02/2,07-1,97/2,07; distância interocular: 1,16/1,14/1,18-1,11/1,18; largura do tilo: $0,57 / 0,56 / 0,60-0,54 / 0,56$.

Tipo e localidade tipo: Holotipo macho de "P. Grossa/Faz. And./Justus/10-46/ Coleção/F. Justus Jor". Parátipos: 1 macho de "P. Grossa (V. Velha) PR/Reserva IAPAR Br 376/Brasil 03.XI.1986/Lev. Ent. PROFAUPAR/Lâmpada"; 1 macho de "Guaiba-RS/30.X.88/Carvalho leg"; 1 macho do Dpto. Zool/UF-Paraná/ Pelotas-Brasil/ RS 30.X.1962/V.O. Becker leg"; 1 fêmea com os mesmos dados do holótipo. O holótipo e os parátipos, com excessão do coletado por "Carvalho", estão depositados no Museu do Departamento de Zoologia da Universidade Federal do Paraná, e, aquele, na coleção do autor.

Descrição: Holótipo Macho. Cabeça 3,33 vezes mais larga que o comprimento do vértice, de cor vermelha, com margens laterais externamente aos ocelos enegrecidas; posclípes e anteclípeo vermelhos; rostro também vermelho, com último artículo negro. Olhos ovalados, transversais, enegrecidos. Vértice mais ou menos liso, brilhante e com pilosidade conspícua, elevado no meio, sem carena, com duas impressōes laterais aos ocelos, iniciando-se no ângulo posterior do tilo, dirigindo-se para trás, até as fóve as, estas bem pronunciadas. Tilo quadrangular mais largo do que longo, com margem anterior algo convexa e posterior sinuosa, com leve elevação mediana. Lobos supra antenais enegrecidos. Ocelos de diâmetro igual a 0,50 do espaço entre eles; mais próximos entre si que dos olhos e margem posterior da cabeça. Antenas negras; escapo, em vista dorsal escondido pelos lobos supra antenais; pedicelo cilíndrico de comprimento 1,5 vezes maior que seu diâmetro, visível por cima, com um conjunto dorso-lateral externo de cerdas; flage- 
lo com corpo basal subcilíndrico, de largura menor que a do pedicelo; estilo longo e fino; arista pouco maior que o diâmetro do corpo basal, implantada inferiormente e no mesmo plano do estilo. Posclípeo intumecido um pouco comprimido lateralmente, superficialmente convexo de perfil, não interrompendo na junção com o anteclípeo, com carena mediana inteira, sulcos transversais evidentes, com fila de cerdas. Anteclípeo razoavelmente comprimido. Rostro atingindo as coxas mesotorácicas.

Pronoto com terço anterior vermelho (algo descolorido pela permanência do espécimen em álcool), o mediano amarelo e o posterior negro; finamente puncturado; pilosidade decumbente; forma hexagonal; levemente arqueado, convexo, sem carena média; duas diminutas impressões junto a linha média e duas grandes laterais a esta, no terço anterior; margem anterior reta, ântero-laterais levemente convexas e arqueadas, póstero-laterais levemente sinuosas e posterior chanfrada. Escutelo triangular, côncavo medianamente e com estrias transversais, de coloração vermelha (descolorido). Tégminas algo transparentes, marron-amarelado escuro, com idêntica pontuação e pilosidade do pronoto; duas manchas no cório, costais, uma no fim do terço anterior, outra no fim do mediano, e uma basal no clavo, amarelas; comprimento igual a 2,77 vezes sua largura; venação razoavelmente distinta; $\mathrm{M}$ e $\mathrm{Cu}$ unidas num curto trajeto, próximo à base. Asas vítreas, venaçăo bem distinta, com 4 células apicais; lobos hamulíferos triangulares, com 2 hâmulos; veia Cul gradualmente alargada na base. Pernas de coloração vermelha, levemente enegrecidas nos tarsos; tíbias posteriores com 2 espinhos laterais, o basal menor, ligeiramente maior que os apicais, estes em número de 10, distribuídos em 2 filas; basitarsos posteriores com 18 espinhos apicais dispostos em uma fileira em forma de "V", com alguns esparsos; postarso com processo subungueal reduzido. Tórax ventralmente vermelho, algo enegrecido. Abdomen vermelho.

Genitália: Pigóforo marron-avermelhado claro, com um dente látero-posterior; placa subgenital bipartida, com extremidacie ponteaguda e igual processo na base dorsalmente; parâmeros com elevação basal e dente distal curvo para cima e para fora; edeago cilíndrico, reto, simples, com dentículos distribuídos por quase toda superfície.

Fếmea, no aspecto geral, idêntica ao macho. Processos basais do ovipositor curtos, gotiformes.

Discussão: esta espécie difere totalmente das demais por apresentar três manchas na tégmina.

\section{AGRADECIMENTOS}

Agradeço ao técnico Arno Kieling Steiger do Instituto de Pesquisas Científicas e Tecnológicas - IPCT - da PUC-RS, por sua dedicação e interesse na confecção das fotografias do presente trabalho.

\section{REFERÊNCIAS BIBLIOGRÄFICAS}

FENNAH, R.G. 1968. Revisionary notes on the new world genera of Cercopid froghoppers (Homoptera:Cercopoidea). Bull. ent. Res., 58 (1): 165-190.

1979. Revisionary notes on the New World genera of cercopid froghoppers (Homoptera:Cercopoidea). II. Bull. ent. Res. 69:267-273. 